\title{
Empirical models of kinetic rate for river treatment analysis of cellulosic materials
}

\author{
Wen-Pei Low ${ }^{\mathrm{a}, *}$, Mohd Fadhil Md Din ${ }^{\mathrm{b}, \mathrm{c}}$, Fung-Lung Chang ${ }^{\mathrm{a}}$, Siti Nur Fatihah Binti Moideen ${ }^{\mathrm{d}}$, \\ Yee Yong Lee ${ }^{\mathrm{e}}$ \\ a Department of Civil Engineering, Faculty of Engineering and Quantity Surveying (FEQS), INTI International University, Persiaran Perdana BBN, Putra Nilai, 71800 Nilai, \\ Negeri Sembilan, Malaysia \\ b Department of Environmental Engineering, Faculty of Civil Engineering, Universiti Teknologi Malaysia, Johor 81310, Malaysia \\ c Centre for Environmental Sustainability and Water Security (IPASA), Research Institute for Environmental Sustainability (RISE), Block C07, Level 2, Universiti Teknologi \\ Malaysia, 81310 UTM Johor Bahru, Malaysia \\ d Graduate School of Environmental Studies, Tohoku University, 6-6-06 Aza-Aoba, Aramaki, Aoba-ku, Sendai, Miyagi 980-8579, Japan \\ e Department of Civil Engineering, Faculty of Engineering,Universiti Malaysia Sarawak, 94300 Kota Samarahan, Sarawak
}

\section{A R T I C L E I N F O}

\section{Keywords:}

Empirical model

Organic compounds

Mass transfer

River water

Cellulosic fibre

\begin{abstract}
A B S T R A C T
The utilisation of cellulosic fibre in removing organic and nutrients pollutants in polluted river is becoming an increasingly popular alternative cost-effective and sustainable option. However, the related empirical models are yet to be fully comprehensive to study the adsorption mechanisms of natural adsorbents. This paper discusses developed empirical model used to estimate the mass transfer of organic pollutants into two natural fibres coconut fibres and oil palm fibres to filter pollutant molecules in water. An empirical model was developed to estimate the mass transfer of organic pollutants in water onto the fibres in a fabricated physical model. The mass transfer relations were derived based on the substrates loading rates and the predicted accumulation rates of substrates in fibres along with the percentage of outflows. Matching empirical results with experimental results showed that the modified model was able to accurately predict the mass transfer rate. The higher adsorption rate of CF (91.02\% COD) depicted greater global mass transfer rate $\left(1.3696 \mathrm{~d}^{-1}\right)$ than OPF $(82.35 \%$ COD) which only had $1.2768 \mathrm{~d}^{-1}$ of global mass transfer rate in $3 \%$ of COD outflow. The contribution of internal diffusion mechanism was significant due to the physical (porosity) and chemical (lignin and cellulosic content) characteristics of both CF and OPF. The study concluded that the performance of biological adsorption using CF and OPF is promising.
\end{abstract}

\section{Introduction}

River has been the source of life since billions of years ago. Early human civilization had mainly flourished at riverbanks, such as Egypt's Nile River, Indus River valley, and along major rivers in China. River forms a vital part of our ecosystem, providing food and shelter to many organisms, not to forget a mean of transportation for human [1]. In order to preserve its sustainability, it is important that river water bodies and riparian zones are maintained clean so that the delicate life balance is not disrupted. Ironically, as human civilization progresses by leaps and bounds throughout history, we are also stressing our river bodies through the tremendous amount of wastes generated. Many of these wastes are disposed irresponsibly into our river systems, overloading the rivers with excessive amount of nutrients that has resulted in harmful algal blooms, dead zones and fish killed [2].
The worsening pollution, fortunately, has also triggered vast amount of research being conducted on water treatment technologies and materials. However, the application of the water and wastewater treatment materials like alum, polymer flocculants, ferric chloride, and coal-prepared activated carbon remains a major challenge for the industry and agricultural sectors due to the high cost involved and the scarcity of equipment [3]. In order to reduce the treatment cost, efforts are now poured into exploring new and novel adsorbents. A notable example is the recycling of readily available agricultural and industrial by-products. These include fly ash bagasse [4], walnut shell [5], waste tires [6], and rice husk [7].

In this regard, coconut fibre (CF) and oil palm fibre (OPF) are natural residual products abundantly available as by-products from the agricultural industry, especially in Malaysia [8,9]. According to the Food and Agriculture Organization of the United Nations (FAU) in year

\footnotetext{
* Corresponding author.

E-mail address: wenpei.low@newinti.edu.my (W.-P. Low).
} 